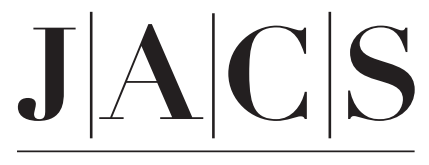

A R T I C L E S

Published on Web 10/11/2003

\title{
Regio- and Enantioselective Alkane Hydroxylation with Engineered Cytochromes P450 BM-3
}

\author{
Matthew W. Peters, ${ }^{\dagger}$ Peter Meinhold, ${ }^{\S}$ Anton Glieder, ${ }^{\ddagger}$ and Frances H. Arnold ${ }^{\dagger, *}$ \\ Contribution from the Division of Chemistry and Chemical Engineering, California Institute of \\ Technology, Pasadena, California 91125 \\ Received June 24, 2003; E-mail: frances@cheme.caltech.edu
}

\begin{abstract}
Cytochrome P450 BM-3 from Bacillus megaterium was engineered using a combination of directed evolution and site-directed mutagenesis to hydroxylate linear alkanes regio- and enantioselectively using atmospheric dioxygen as an oxidant. BM-3 variant 9-10A-A328V hydroxylates octane at the 2-position to form $S$-2-octanol $(40 \%$ ee). Another variant, $1-12 \mathrm{G}$, also hydroxylates alkanes larger than hexane primarily at the 2-position but forms $R$-2-alcohols $(40-55 \%$ ee). These biocatalysts are highly active (rates up to $400 \mathrm{~min}^{-1}$ ) and support thousands of product turnovers. The regio- and enantioselectivities are retained in whole-cell biotransformations with Escherichia coli, where the engineered P450s can be expressed at high levels and the cofactor is supplied endogenously.
\end{abstract}

\section{Introduction}

Cytochromes P450 comprise a superfamily of enzymes with well over a thousand members that are, as a whole, capable of oxidizing an immense variety of organic molecules in vivo using atmospheric dioxygen as an oxidant. ${ }^{1,2}$ Conversion of even a small fraction of these P450 systems into useful synthetic catalysts, however, is limited by several factors, including the multicomponent nature of most of these enzymes, the fact that most are membrane-bound, their limited stabilities, and their generally slow rates. The few bacterial cytochrome P450s that have been characterized are in general faster, soluble (i.e., not membrane-bound), more stable, expressible in Escherichia coli, and structurally characterized. ${ }^{3}$ In addition to possessing these useful properties, the bacterial cytochrome P450 BM-3 from Bacillus megaterium, in contrast to almost all other characterized P450 systems, is comprised of a single polypeptide chain. ${ }^{4}$ Inspired by the diversity of activities supported by the P450 scaffold in nature, our laboratory has focused on engineering BM-3 to generate practical P450-based oxidation catalysts. In particular, we are interested in creating useful biocatalysts for the controlled oxidation of alkanes.

Linear alkanes are difficult to hydroxylate: the alkane $\mathrm{C}-\mathrm{H}$ bond is notoriously inert because of its high ( $\sim 97 \mathrm{kcal} / \mathrm{mol})$ bond strength, making alkanes ideal solvents for use with very

$\dagger$ Division of Chemistry and Chemical Engineering, California Institute of Technology.

$\S$ Biochemistry and Molecular Biophysics Graduate Option, California Institute of Technology.

$\doteqdot$ Current address: Institute of Biotechnology, Technical University of Graz, Petersgasse 12, A-8010 Graz, Austria.

(1) Lewis, D. F. V.; Watson, E.; Lake, B. G. Mutat. Res. 1998, 410, 242270 .

(2) Sono, M.; Roach, M. P.; Coulter, E. D.; Dawson, J. H. Chem. Rev. 1996, 96, 2841-2888.

(3) Urlacher, V.; Schmid, R. D. Curr. Opin. Biotechnol. 2002, 13, 557-564.

(4) Munro, A. W.; Leys, D. G.; McLean, K. J.; Marshall, K. R.; Ost, T. W. B.; Daff, S.; Miles, C. S.; Chapman, S. K.; Lysek, D. A.; Moser, C. C.; Page, C. C.; Dutton, P. L. Trends Biochem. Sci. 2002, 27, 250-257.

13442 — J. AM. CHEM. SOC. 2003, 125, 13442-13450 reactive oxidation catalysts..$^{5}$ Additionally, the activation energies for subsequent oxidations of an alcohol are similar to the energy required for the initial hydroxylation of the starting alkane, resulting in mixtures of alcohol, ketone/aldehyde, and carboxylic acid products in most alkane oxidation reactions. The similarity of methylene $\mathrm{C}-\mathrm{H}$ bond strengths in a linear alkane and the lack of functional groups that can serve to direct catalysis make selective hydroxylation of these compounds especially challenging. Limited selective alkane hydroxylation has been reported for bulky cycloalkanes and aryl alkanes using biomimetic transition-metal complexes as catalysts and peroxides as oxidants, but these complexes do not produce hydroxylated products in useful amounts (the catalysts support very few $(<20)$ total turnovers). ${ }^{6-9}$

Several biological systems are capable of dioxygen-supported alkane hydroxylation and, in some cases, even regioselective alkane hydroxylation. For example, the particulate methane monooxygenase from Methylococcus capsulatus (Bath) can hydroxylate butane and pentane to yield primarily $R$-2-alcohols. ${ }^{10}$ This enzyme does not accept larger alkanes. Soluble methane monooxygenase from the same organism hydroxylates several alkanes with little or no selectivity. ${ }^{11}$ Neither enzyme is likely to serve as a practical biocatalyst because of their inability to be overexpressed in a suitable host organism and their rather low intrinsic activities. In contrast, alkane hydroxylase B (AlkB) from Pseudomonas oleovorans hydroxylates octane selectively at the terminal (or $\omega$ ) position to make

(5) Kerr, J. A. Chem. Rev. 1966, 66, 465-500

(6) Chavez, F. A.; Rowland, J. M.; Olmstead, M. M.; Mascharak, P. K. J. Am Chem. Soc. 1998, 120, 9015-9027.

(7) Blay, G.; Fernandez, I.; Gimenez, T.; Pedro, J. R.; Ruiz, R.; Pardo, E. Lloret, F.; Munoz, M. C. Chem. Commun. 2001, 2102-2103.

(8) Chen, K.; Que, Jr., L. J. Am. Chem. Soc. 2001, 123, 6327-6337.

(9) Assis, M. D.; Smith, J. R. L. J. Chem. Soc., Perkin Trans. 2 1998, $2221-$ 2226

(10) Elliott, S. J.; Zhu, M.; Tso, L.; Nguyen, H. T.; Yip, J. H.; Chan, S. I. J. Am. Chem. Soc. 1997, 119, 9949-9955.

(11) Wallar, B. J.; Lipscomb, J. D. Chem. Rev. 1996, 96, 2625-2658.

10.1021/ja0303790 CCC: $\$ 25.00$ @ 2003 American Chemical Society 


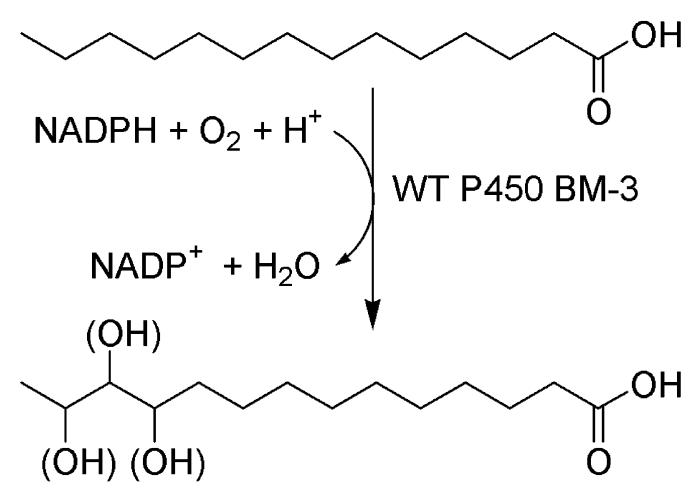

Figure 1. General hydroxylation reaction catalyzed by cytochrome $\mathrm{P} 450 \mathrm{~s}$. Hydroxylation of myristic acid by wild-type cytochrome $\mathrm{P} 450 \mathrm{BM}-3$ results in $54 \% \omega-1,25 \% \omega-2$, and $20 \% \omega-3$ hydroxylation product. ${ }^{24}$

1-octanol, and is used in engineered whole cells to generate this product on an industrial scale. ${ }^{12}$ Terminal alkane hydroxylation was also reported in some mammalian liver P450s, including rabbit liver P450 CYP4B $1 .{ }^{13}$ Nonselective cytochrome P450 alkane hydroxylation systems include the site-directed mutants of $\mathrm{P} 450_{\text {cam }}$ of Wong and co-workers ${ }^{14-16}$ and an engineered P450 BM-3 reported by our group. ${ }^{17,18}$ Enantioselective (but not regioselective) hydroxylation of alkanes has been reported with whole-cell systems of soil bacteria genera such as Bacillus, ${ }^{19}$ Pseudomonas, ${ }^{20,21}$ and Rhodococcus, ${ }^{22,23}$ but the selectivity observed in these systems is most likely due to metabolism of specific isomers rather than the action of selective oxygenases.

The natural substrates of cytochrome P450 BM-3 are medium-chain (C12 to $\mathrm{C} 18)$ fatty acids, which are hydroxylated at their $\omega-1, \omega-2$, and $\omega-3$ positions using atmospheric dioxygen and nicotinamide adenine dinucleotide phosphate (NADPH) (Figure 1). ${ }^{24}$ Substrate is bound and hydroxylated in a hydrophobic pocket positioned directly above the heme cofactor in the P450 heme, or hydroxylase, domain. A peptide linker connects the P450 BM-3 heme domain to the reductase domain, where NADPH is reduced and flavin mononucleotide (FMN) and flavin adenine dinucleotide (FAD) cofactors are used to transfer electrons to the heme active site for catalysis. In previous work, we used directed evolution to convert wild-type BM-3 into a fast, but nonselective, alkane hydroxylase called 139-3. ${ }^{17,18}$ A large increase in activity toward alkanes as small

(12) Mathys, R. G.; Schmid, A.; Witholt, B. Biotechnol. Bioeng. 1999, 64, 459477.

(13) Fisher, M. B.; Zheng, Y.; Rettie, A. E. Biochem. Biophys. Res. Commun. 1998, 248, 352-355.

(14) Stevenson, J.; Westlake, A. C. G.; Whitlock, C.; Wong, L. J. Am. Chem. Soc. 1996, 118, 12846-12847.

(15) Bell, S. G.; Stevenson, J.; Boyd, H. D.; Campbell, S.; Riddle, A. D.; Orton, E. L.; Wong, L. Chem. Commun. 2002, 490-491.

(16) Bell, S. G.; Orton, E. L.; Boyd, H. D.; Stevenson, J.; Riddle, A. D.; Campbell, S.; Wong, L. J. Chem. Soc., Dalton Trans. 2003, 2133-2140.

(17) Farinas, E. T.; Schwaneberg, U.; Glieder, A.; Arnold, F. H. Adv. Synth. Catal. 2001, 343, 601-606.

(18) Glieder, A.; Farinas, E. T.; Arnold, F. H. Nat. Biotechnol. 2002, 20, 11351139.

(19) Adam, W.; Lukacs, Z.; Saha-Moller, C. R.; Weckerle, B.; Schreier, P. Eur. J. Org. Chem. 2000, 2923-2926.

(20) Arp, D. J. Microbiology 1999, 145, 1173-1180.

(21) Steffan, R. J.; McClay, K.; Vainberg, S.; Condee, C. W.; Zhang, D. Appl. Environ. Microbiol. 1997, 63, 4216-4222.

(22) Kulikova, A. K.; Bezborodov, A. M. Appl. Biochem. Microbiol. 2000, 36, $227-230$.

(23) Kulikova, A. K.; Bezborodov, A. M. Appl. Biochem. Microbiol. 2001, 37, 164-167.

(24) Ost, T. W. B.; Munro, A. W.; Mowat, C. G.; Taylor, P. R.; Pesseguiero, A.; Fulco, A. J.; Cho, A. K.; Cheesman, M. A.; Walkinshaw, M. D.; Chapman, S. K. Biochemistry 2001, 40, 13430-13438. as propane was observed after five rounds of directed evolution experiments, which accumulated 11 amino acid substitutions in the heme domain.

We have begun to explore the further evolution of P450 BM-3 to hydroxylate very small alkanes such as ethane and methane, activities never reported in a cytochrome P450, by applying a combination of directed evolution and site-directed mutagenesis. The mutants obtained from these experiments hydroxylate propane at faster rates and reach higher total turnover numbers than 139-3. Of particular interest, we found that two of these mutants are highly regioselective and enantioselective toward longer alkanes. One mutant forms $R$-2alcohols from alkanes bigger than heptane, and the other forms $S$-2-octanol from octane. The engineered P450 BM-3 enzymes described here are, to our knowledge, the only systems capable of direct, regio-, and enantioselective hydroxylation of linear alkanes expressed in hosts suitable for large-scale biocatalytic processes.

\section{Results and Discussion}

Directed Evolution. In our previous work with this enzyme, five rounds of directed evolution starting with wild-type cytochrome P450 BM-3 yielded the alkane hydroxylase 139$3 .{ }^{18}$ In each round, a library of randomly mutated BM-3 enzymes was screened for octane hydroxylation activity on the "surrogate" substrate $p$-nitrophenyl octyl ether. Hydroxylation of this substrate at the carbon atom containing the $p$-nitrophenoxy moiety results in the formation of $p$-nitrophenolate, which was used for colorimetric identification of active mutants. Active mutants were then tested for octane hydroxylation activity, and the most active ones were used as parents for subsequent rounds of evolution. In some cases, several active mutants were isolated from a single round of screening and recombined using DNA shuffling to obtain the parent for the next round. In these and the evolution experiments described in this work, random mutagenesis and recombination were applied only to the heme domain (residues 1-429, with 429 chosen for the convenience of introducing a $\mathrm{SacI}$ restriction site into the heme domain gene); the reductase domain was left untouched. The complete BM-3 enzyme (modified heme domain attached to the unmodified reductase domain) was used in all the experiments described here.

Of the 11 amino acid substitutions in the alkane hydroxylase 139-3 heme domain, only one (V78A) occurs at a residue that contacts the fatty acid substrate in the (wild-type) enzyme. ${ }^{18}$ The mechanisms by which the mutations contribute to the new activity are difficult to rationalize. The rather broad distribution of 139-3's hydroxylated alkane products, however, suggests that its active site is rather large and that its alkane substrates are "loosely" bound. This is not surprising since the surrogate substrate used to identify these mutants is quite large relative to octane, the intended substrate. The one active-site substitution, in fact, replaces valine with a smaller, alanine side chain.

P450 BM-3 mutant 139-3 shows significant activity on propane, even though small alkane substrates were not used to screen the mutant libraries in the directed evolution experiments. To improve this activity further, and perhaps even achieve activity toward ethane, we continued to apply iterative rounds of mutagenesis and screening, using propane. The BM-3catalyzed hydroxylation reaction results in the oxidation of 1 
Table 1. Amino Acid Substitutions in P450 BM-3 Mutants

\begin{tabular}{llcccccc}
\hline $\begin{array}{c}\text { position } \\
\text { (WT) }\end{array}$ & $\begin{array}{c}\text { DNA } \\
\text { mutation }\end{array}$ & $\begin{array}{c}139-3 \\
\text { aa }\end{array}$ & $\begin{array}{c}\text { J } \\
\text { aa }\end{array}$ & $\begin{array}{c}\text { 9-10A } \\
\text { aa }\end{array}$ & $\begin{array}{c}\text { 9-10A-A82L } \\
\text { aa }\end{array}$ & $\begin{array}{c}\text { 9-10A-A328V } \\
\text { aa }\end{array}$ & $\begin{array}{c}1-12 G \\
\text { aa }\end{array}$ \\
\hline R47 & C142T & & & C & C & C & C \\
V78 & T236C & A & A & A & A & A & A \\
A82 & $247-249 a$ & & & & L & & L \\
K94 & A284T & & & I & I & I & I \\
F107 & C324T & F & F & F & F & F & F \\
H138 & & Y & & & & & \\
P142 & C427T & & & S & S & S & S \\
T175 & C527T & I & I & I & I & I & I \\
V178 & & I & & & & & \\
A184 & C554T & V & V & V & V & V & V \\
F205 & T617G & & C & C & C & C & C \\
S226 & C681G & & R & R & R & R & R \\
H236 & T711G & Q & Q & Q & Q & Q & Q \\
E252 & A758G & G & G & G & G & G & G \\
R255 & C766A & S & S & S & S & S & S \\
A290 & C872T & & V & V & V & V & V \\
A295 & & T & & & & & \\
A328 & C986T & & & & & V & V \\
L353 & C1060G & V & V & V & V & V & V \\
E372 & A1119G & & E & E & E & E & E \\
\hline
\end{tabular}

a A82L DNA mutation was GCA to CTT.

equiv of NADPH for each equivalent of hydroxylated substrate. Using a 96-well plate reader, we can monitor spectrophotometrically at $340 \mathrm{~nm}$ the rate of NADPH oxidation in the presence of BM-3-containing cell lysate and substrate to quickly identify mutants with high activity toward any given substrate. ${ }^{25}$ It is possible that the reducing equivalents of NADPH become uncoupled to substrate oxidation, leading to false positives in a mutant library, but gas chromatographic analysis of reaction mixtures can confirm when an increased NADPH oxidation rate is accompanied by more or faster product formation.
For the first round of directed evolution, a library of P450 BM-3 variants was generated by recombining mutant 139-3 with 15 other mutants from the same generation that also exhibited increased activity toward $p$-nitrophenyl octyl ether and octane. The shuffled gene library was transformed into E. coli (DH5 $\alpha)$ competent cells, where the enzymes were overexpressed. Aliquots of the cell-free extracts from individual clones were transferred to 96-well plates, where NADPH consumption was monitored in the presence of propane. Positive clones were grown up and their enzymes purified for comparative analysis using gas chromatography. Mutant $\mathrm{J}$ was selected on the basis of its increased rate of NADPH consumption in the presence of propane. This increased rate corresponded to an increase (relative to 139-3) in total production of hydroxylated products with the substrates propane (800 turnovers) and octane (3000 turnovers).

Error-prone PCR of the gene for P450 BM-3 mutant J, performed under conditions designed to yield 1-2 mutations on average per gene, generated the library for the second round of directed evolution. Mutant 9-10A was selected from this library for its increased NADPH consumption rate in the presence of propane; it was subsequently shown to support more turnovers of propane (1100). The sequences and properties of these mutants are detailed in Tables $1-3$ and Figure 2. Neither J nor 9-10A acquired active-site mutations, nor did they show major changes in regioselectivity toward longer alkanes, compared to 139-3. Although these mutants supported more turnovers, their coupling efficiencies (see below) were not improved.

Random mutagenesis of 9-10A generated the library for a third round of evolution. This time, a second screen was applied

Table 2. Product Distributions (\% total alcohols ${ }^{a}$ ) and $\%$ ee of Selected Products

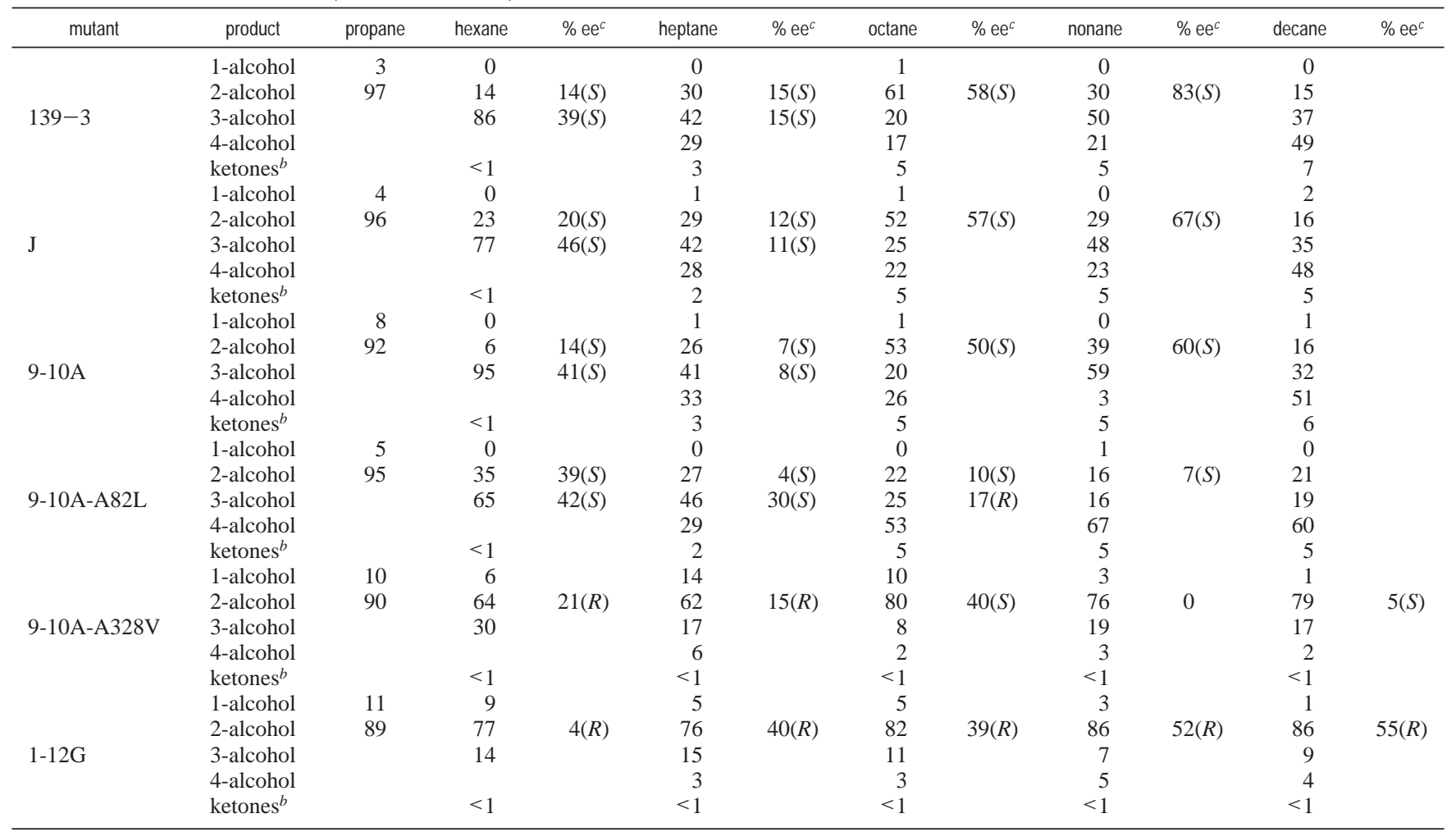

a Product distribution determined as ratio of a specific alcohol product to the total amount of all alcohol products (given in $\%$ ). Errors are at most $\pm 1 \%$. $b$ Product distribution for ketones was similar to alcohol product distribution. The numbers reported here are the (\%) total of all ketones relative to total products (alcohols + ketones). ${ }^{c}$ Favored enantiomer is listed in parentheses. Errors are at most $\pm 5 \%$. 
Table 3. Catalytic Properties of Mutants of P450 BM-3

\begin{tabular}{|c|c|c|c|c|c|c|}
\hline mutant & substrate & $\begin{array}{c}\text { rate of NADPH } \\
\text { consumption }\left(\mathrm{min}^{-1}\right)^{a}\end{array}$ & $\begin{array}{c}\text { rate of product } \\
\text { formation }\left(\mathrm{min}^{-1}\right)^{c}\end{array}$ & $\begin{array}{l}\text { coupling to } \\
\text { NADPH }(\%)^{d}\end{array}$ & $\begin{array}{c}\text { total } \\
\text { turnovers }\end{array}$ & $\begin{array}{c}\text { fold } \\
\text { improvement }{ }^{g}\end{array}$ \\
\hline \multirow[t]{2}{*}{$139-3$} & octane & $2200^{b}$ & 480 & 22 & 1000 & 1 \\
\hline & propane & $140^{b}$ & 12 & 9 & 500 & 1 \\
\hline \multirow[t]{2}{*}{$\mathrm{J}$} & octane & 2900 & 660 & 23 & 3000 & 3 \\
\hline & propane & 610 & 30 & 5 & 800 & 1.6 \\
\hline \multirow[t]{2}{*}{$9-10 \mathrm{~A}$} & octane & 2600 & 540 & 21 & 3000 & 3 \\
\hline & propane & 420 & 23 & 5 & 1100 & 2.2 \\
\hline \multirow[t]{2}{*}{ 9-10A-A82L } & octane & 1400 & 530 & 38 & 6000 & 6 \\
\hline & propane & 190 & 54 & 28 & 2400 & 4.8 \\
\hline \multirow[t]{2}{*}{ 9-10A-A328V } & octane & 1200 & 50 & 4 & 2000 & 2 \\
\hline & propane & 320 & 35 & 11 & 100 & 0.2 \\
\hline \multirow{2}{*}{$1-12 \mathrm{G}$} & octane & 410 & 150 & 37 & 7500 & 7.5 \\
\hline & propane $f$ & 20 & 160 & $100^{f}$ & 6000 & 12 \\
\hline
\end{tabular}

a Initial NADPH consumption rates were measured over $15 \mathrm{~s}$ at $340 \mathrm{~nm}$ as $\mathrm{nmol}$ NADPH/min/nmol protein. Octane reactions contained $100 \mathrm{nM}$ P450, $166 \mu \mathrm{M}$ NADPH, and $4 \mathrm{mM}$ octane in $1 \%$ ethanol and potassium phosphate buffer. Propane reactions contained $200 \mathrm{nM}$ P450, $166 \mu \mathrm{M}$ NADPH, and propane-saturated potassium phosphate buffer. Errors are at most $10 \% .^{b}$ The difference between these numbers and ones we reported previously are due to the longer time period used to measure rates in this work (15 s compared to $2 \mathrm{~s}){ }^{c}$ Initial rates were measured by GC over 1 min as nmol total products/ $\mathrm{min} / \mathrm{nmol}$ protein. Octane reactions contained $100 \mathrm{nM} \mathrm{P} 450,500 \mu \mathrm{M}$ NADPH, and $4 \mathrm{mM}$ octane in $1 \%$ ethanol and potassium phosphate buffer. Propane reactions contained $1 \mu \mathrm{M}$ P450, $500 \mu \mathrm{M}$ NADPH, and propane-saturated potassium phosphate buffer. Errors are at most $10 \%$. $d$ Coupling determined by ratio of product formation rate to NADPH consumption rate. ${ }^{e}$ Total turnover numbers determined as nmol product/nmol enzyme. Octane reactions contained 10-25 nM P450, $500 \mu \mathrm{M}$ NADPH, and $4 \mathrm{mM}$ octane in $1 \%$ ethanol and potassium phosphate buffer. Propane reactions contained $10-25 \mathrm{nM}$ protein, potassium phosphate buffer saturated with propane, and an NADPH regeneration system containing $100 \mu \mathrm{M} \mathrm{NADP}+, 2$ units/mL of isocitrate dehydrogenase, and $10 \mathrm{mM}$ isocitrate. Errors are at most $10 \% . f$ The NADPH consumption rate with propane was only 20 min ${ }^{-1}$ faster than the background rate without substrate. The higher propanol formation rate suggests that propane hydroxylation with this mutant outcompetes the background NADPH consumption process. ${ }^{g}$ Fold improvement is based on total turnovers of hydroxylated products compared to 139-3.
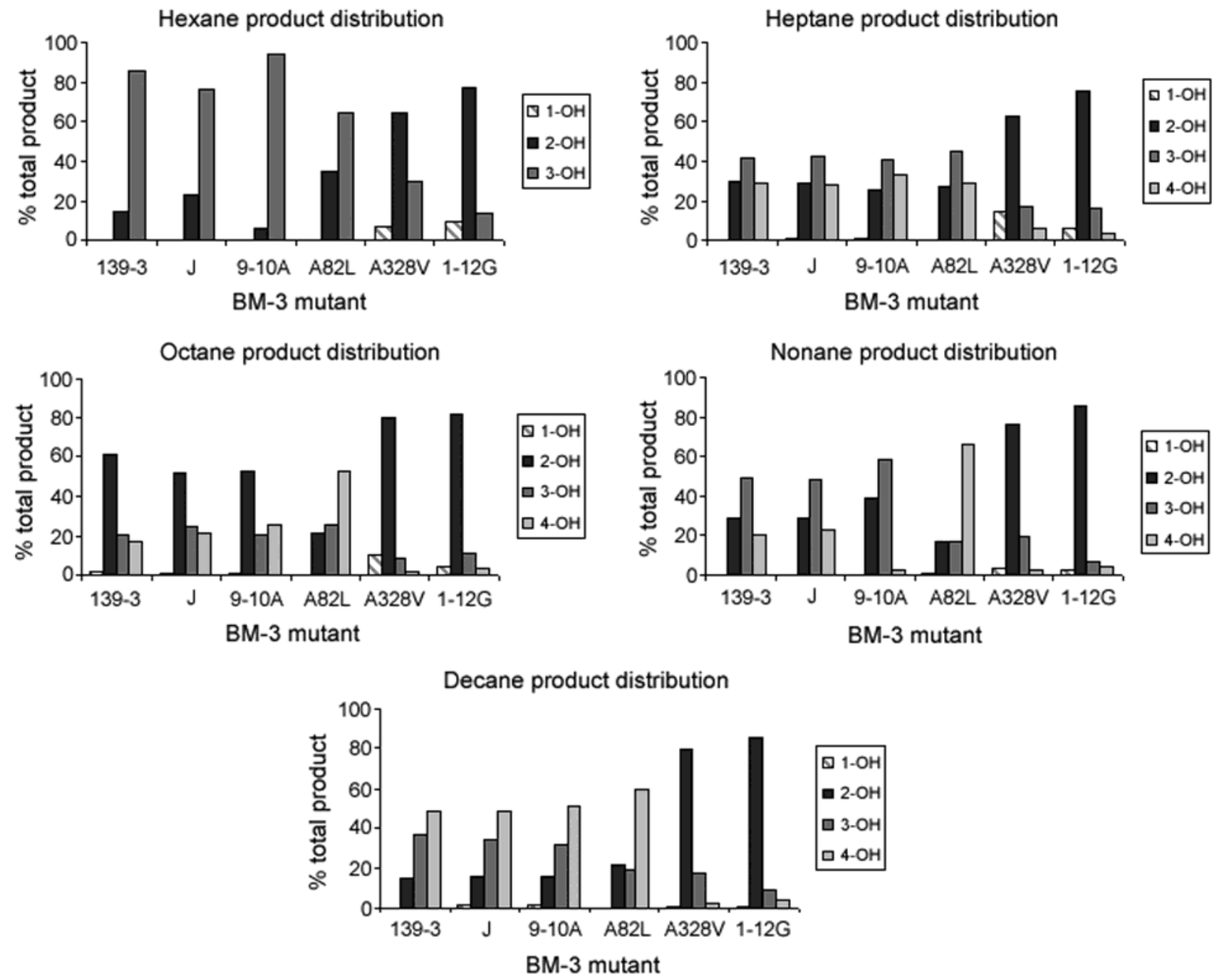

Figure 2. Hydroxylation product distribution of BM-3 mutants. Mutants 9-10A-A82L and 9-10A-A328V are abbreviated A82L and A328V, respectively.

to assess the amount of hydroxylation products generated by each mutant. This screen uses the surrogate substrate dimethyl ether, which is similar to propane in size and $\mathrm{C}-\mathrm{H}$ bond strength. Upon hydroxylation, dimethyl ether forms formaldehyde, which can be detected with Purpald dye ${ }^{26}$ (Figure 3 ). This third round failed to produce a mutant with either increased 
a)

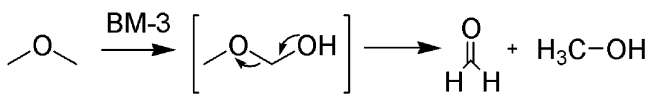

b)

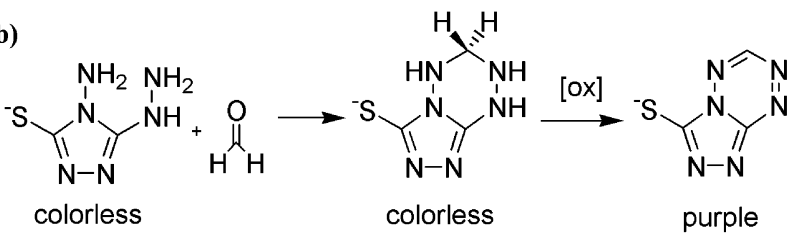

Figure 3. (a) Hydroxylation of surrogate substrate dimethyl ether produces formaldehdye. (b) Purpald reacts with formaldehyde to form a purple adduct upon air oxidation.

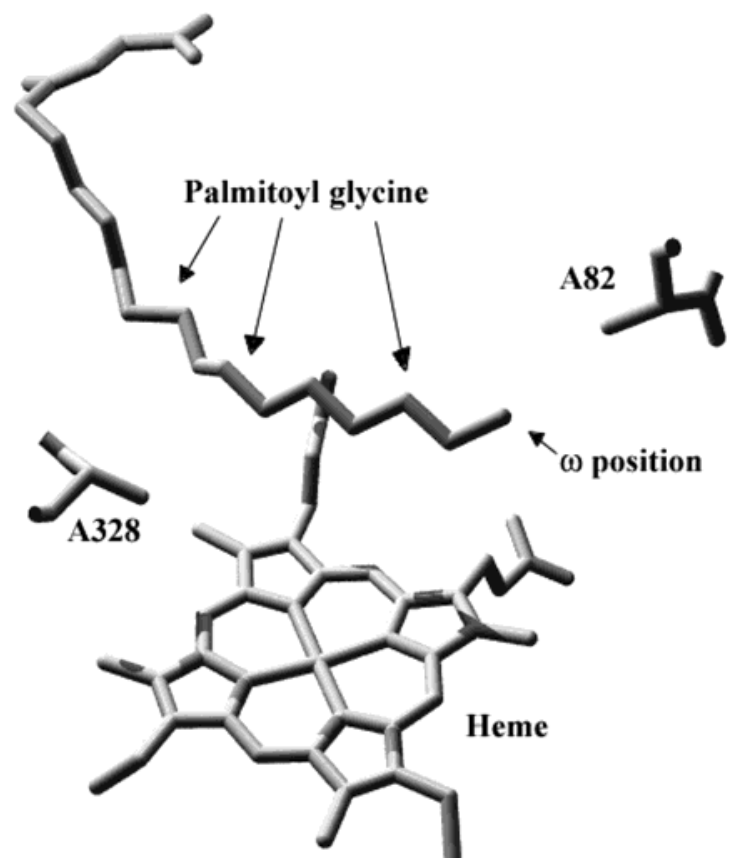

Figure 4. Positions of A328 and A82 in the active site of wild-type cytochrome P450 BM-3. The picture was made from the coordinates of the crystal structure 1JPZ in the Protein Database. The substrate is palmitoyl glycine.

propane hydroxylation activity or more propane hydroxylation products. A possible explanation is that further increases in activity require two or more simultaneous, or coupled, genetic mutations. Such events occur with very low probability and will not be found by screening a few thousand clones.

Site-Directed Mutagenesis. Wong et al. achieved hydroxylation activity toward butane and propane in the camphor hydroxylase cytochrome $\mathrm{P} 450_{\text {cam }}$ by reducing the size of the enzyme's active site using site-directed mutagenesis. ${ }^{15} \mathrm{We}$ reasoned that decreasing the volume of the active site of 139-3 might serve to enhance its activity toward smaller substrates. Tightening up the active site might also confer regioselectivity toward longer alkanes; if the substrate is bound more tightly, fewer hydroxylation products should be possible. We therefore turned to site-directed mutagenesis of residues in the active site for further improvements.

Using a crystal structure of the heme domain of wild-type BM-3 containing a bound substrate, ${ }^{27}$ we identified two residues that should influence substrate binding (Figure 4). Alanine 328 sits directly above the heme cofactor and is the residue closest to the proximal side of the heme iron. Mutation of this residue to valine in the wild-type enzyme had been reported to affect substrate binding and turnover rates on fatty acids. ${ }^{28} \mathrm{We}$ substituted alanine 328 in $9-10$ A with the larger, hydrophobicvaline and determined the activity of this mutant (termed 9-10A-A328V) toward several alkanes (Tables 2 and 3; Figure 2 ). Neither the propane hydroxylation activity nor the total propane turnovers improved relative to its parent. However, we observed a dramatic shift in the regioselectivity of hydroxylation on longer alkanes (Figure 2). Wild type and all mutants of BM-3 generated in this laboratory by directed evolution hydroxylate longer alkanes such as heptane, octane, and nonane with roughly equivalent distributions of the 2-, 3-, and 4-alcohols. Mutant $9-10 \mathrm{~A}-\mathrm{A} 328 \mathrm{~V}$, on the other hand, forms primarily $(>80 \%)$ 2 -alcohols from these substrates. With octane, the resulting 2-alcohol is $\sim 70 \%$ S-2-octanol ( $40 \%$ ee) (Tables 2 and 3; Figure $2)$. Other alkanes are not hydroxylated enantioselectively. We rationalize that these changes in regioselectivity and enantioselectivity result from a reduction in possible binding geometries for these substrates in the active site.

The alkane hydroxylation product distributions for 9-10AA328V clearly show its selectivity for the alkane 2-position. The fact that only 2-octanol is formed enantioselectively, but not 2-heptanol or 2-nonanol, suggests that a substrate-protein contact specific to the methyl group of octane furthest from the heme induces enantioselectivity toward this lone substrate. The other nonregioselective mutants, 139-3, J, and 9-10A, also exhibit similar enantioselectivity toward octane; this contact must therefore function independently of residue 328. It may be possible to engineer a mutant that is enantioselective for the $S$-2-position of other alkanes by changing other residues in the binding pocket (or outside) to mimic this contact.

The second side chain we chose to alter is located near the active site that forms after the conformational change associated with substrate binding occurs. In the crystal structure of BM-3 with bound palmitoyl glycine, alanine 82 is located within 3.5 $\AA$ of the substrate $\omega$-terminus. ${ }^{27} \mathrm{We}$ reasoned that changing this residue to a larger, hydrophobic amino acid would decrease active-site volume upon substrate binding. Lacking information to choose an appropriate replacement, we prepared a small library containing the four large, hydrophobic amino acids leucine, isoleucine, valine, and phenylalanine at position 82 and screened the library using dimethyl ether. Mutant 9-10A-A82L was identified as more active, and subsequent gas chromatographic analysis of the reaction mixtures revealed that this mutant supports more turnovers with propane $(\sim 2400)$ than the 9-10A parent. The rate of propane hydroxylation and its coupling efficiency with this mutant were also improved. Hydroxylation of longer alkanes using this mutant occurred with a small shift in regioselectivity, in this case favoring the formation of primarily 3- and 4-alcohols (Figure 2).

Recombination. Next, we shuffled the (heme domain) genes of J, 9-10A, 9-10A-A328V, and 9-10A-A82L and screened that library for activity on propane and dimethyl ether. Mutant $1-12 \mathrm{G}$ was selected from this library. As with mutant 9-10A-A328V, $1-12 \mathrm{G}$ hydroxylates alkanes at the 2-position (>80\%). However,

(25) Glieder, A.; Meinhold, P. In Directed Enzyme Evolution: Screening and Selection Methods; Arnold, F. H., Georgiou, G., Eds.; Humana Press: Totowa, NJ, 2003; Vol. 230, pp 157-170

(26) Hopps, H. B. Aldrichimica Acta 2000, 33, 28-30.

(27) Haines, D. C.; Tomchick, D. R.; Machius, M.; Peterson, J. A. Biochemistry 2001, 40, 13456-13465.

(28) Peterson, J. A.; Hedge, A.; Graham, S.; Mullin, D. Presented at the Sixth International Symposium on Cytochrome P450 Biodiversity, UCLA, Los Angeles, CA, Aug 2002. 


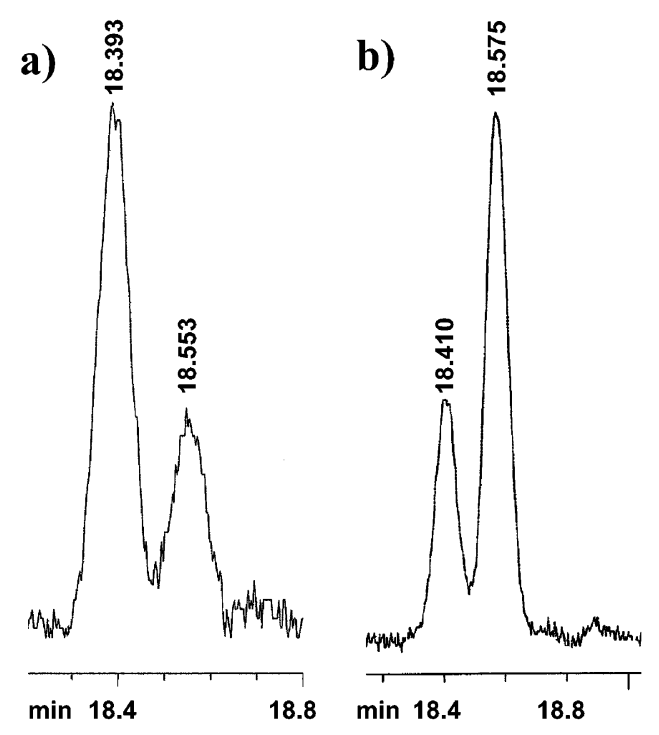

Figure 5. GC/FID analysis of the (-)-menthyl carbonate diastereomers of the 2-octanol produced by mutant BM-3-catalyzed alkane oxidation. The $S$-2-octanol derivative elutes at $18.4 \mathrm{~min}$, the $R$-2-octanol derivative elutes at $18.6 \mathrm{~min}$. (a) Reaction catalyzed by $9-10 \mathrm{~A}-\mathrm{A} 328 \mathrm{~V}$ (40\% ee). (b) Reaction catalyzed by $1-12 \mathrm{G}(40 \%$ ee).

chiral GC analysis of the products revealed that $1-12 \mathrm{G}$ is as enantioselective as $9-10 \mathrm{~A}-\mathrm{A} 328 \mathrm{~V}$, generating the $R$-2-alcohols (40-55\% ee) of heptane, octane, nonane, and decane (Tables 2 and 3; Figure 2). Mutant 1-12G also supports thousands of turnovers on the substrates propane (6000) and octane (7500), resulting in approximately 1 order of magnitude improvement compared to 139-3. Sequencing revealed that this mutant contains all of the mutations introduced into the recombination library: it is the double mutant A328V + A82L of 9-10A. Addition of the A82L mutation to 9-10A-A328V has shifted the octane substrate in the active site such that the opposite enantiomer of its 2-alcohol is now favored (Figure 5). Residue 82 was chosen for its proximity to the substrate $\omega$-terminus, but it is not clear whether the larger leucine side chain "pushes" the substrate further up the active site or blocks the channel such that the substrate is flipped relative to its position in the A328V mutant.

In addition to its effect on selectivity, the A82L substitution, both with and without the A328V mutation, at least doubles the stability of the catalyst, as determined by total turnover number and increases its coupling to NADPH oxidation (Table $3)$. It is possible that this mutation protects the heme cofactor from degradation by reduced oxygen species such as peroxide and superoxide (see below), but further analysis beyond the scope of this report will be required to determine the cause.

Coupling of NADPH-Reducing Equivalents to Product Formation. Under oxygen-limiting conditions, i.e., substrate and NADPH concentrations in large excess of the 225-250 $\mu \mathrm{M}$ dioxygen present in oxygen-saturated buffer, hydroxylation reactions catalyzed by the mutants in this work form 225-250 $\mu \mathrm{M}$ of products. This upper limit to product formation suggests, as we have reported in our previous work, that substrate oxidation is tightly coupled to the consumption of dioxygen in these mutants. In general with P450 systems, NADPH oxidation not coupled to the formation of product is assumed to be wasted on reducing heme-bound dioxygen to active oxygen species such as peroxide and superoxide (which may subsequently inactivate the enzyme) or to water. If oxygen reduction is the only mechanism for NADPH uncoupling, then our mutants should be fully coupled. When we compare the NADPH consumption rates of these mutants (in the presence of substrate) with their product formation rates, however, we discover that a large fraction of the NADPH oxidized is not used for product formation or uncoupled oxygen reduction (Table 3). We are currently investigating the fate of these lost electrons, but have noticed that when we screen for product formation using the dimethyl ether/purpald screen, the resulting mutants, $1-12 \mathrm{G}$ and 9-10A-A82L, are more coupled than mutants obtained by screening for NADPH consumption only and also support more total turnovers.

Whole-Cell Biotransformations. Two major practical obstacles to implementing a biocatalytic process are the need for large amounts of purified protein and the expensive cofactors. Lysates of $E$. coli (DH5 $\alpha$ ) containing overexpressed cytochrome P450 BM-3 mutants exhibit the same activity as purified protein (data not shown) but still require the addition of NADPH. We have used an isocitrate dehydrogenase-based NADPH-regenerating system ${ }^{29}$ to perform reactions using both cell lysate and purified protein, with results indistinguishable from using NADPH alone (consistent with the fact that these reactions are generally oxygen-limited; data not shown). We were curious to see if we could use our E. coli system as a whole-cell catalyst, since the alkane substrates and alcohol products should be permeable to the cell membrane. To test this, we prepared cultures of DH5 $\alpha$ cells that overexpress the 9-10A-A $328 \mathrm{~V}$ and the $1-12 \mathrm{G}$ mutants. Without optimizing the system, we prepared the cells and supplied them octane according to a procedure published by Witholt's group that had used E. coli K27 expressing wild-type BM-3 and myristic acid as a substrate. ${ }^{30,31}$ We used isopropyl- $\beta$-D-thiogalactopyranoside (IPTG) to induce expression. Extraction of these whole-cell reaction mixtures with methylene chloride and analysis of the products revealed that both the regio- and enantioselectivity of the alkane hydroxylation products are preserved in the whole-cell system (Figure 6). Optimization of these reaction conditions, perhaps using a system analogous to the two-phase system described by Witholt and co-workers for AlkB octane hydroxylation, ${ }^{12}$ could lead to cost-effective use of our $E$. coli cells for alkane hydroxylation.

\section{Conclusions}

Cytochrome P450 BM-3 is a highly "evolvable" catalyst: protein engineering by directed evolution and site-directed mutagenesis has generated variants with wide-ranging properties, including the ability to utilize different oxidants such as hydrogen peroxide for fatty acid hydroxlation, ${ }^{32,33}$ activity on non-natural substrates ${ }^{34-37}$ and in organic solvents, ${ }^{38}$ and greater

(29) Schwaneberg, U.; Otey, C.; Cirino, P. C.; Farinas, E.; Arnold, F. H. J. Biomol. Screening 2001, 6, 111-117.

(30) Schneider, S.; Wubbolts, M. G.; Sanglard, D.; Witholt, B. Tetrahedron: Asymmetry 1998, 9, 2833-2844.

(31) Schneider, S.; Wubbolts, M. G.; Oesterhelt, G.; Sanglard, D.; Witholt, B. Biotechnol. Bioeng. 1999, 64, 333-340.

(32) Cirino, P. C.; Arnold, F. H. Adv. Synth. Catal. 2002, 344, 932-937.

(33) Cirino, P. C.; Arnold, F. H. Angew. Chem., Int. Ed. 2003, 42, 3299-3301.

(34) Appel, D.; Lutz-Wahl, S.; Fischer, P.; Schwaneberg, U.; Schmid, R. D. J. Biotechnol. 2001, 88, 167-171.

(35) Li, Q. S.; Ogawa, J.; Schmid, R. D.; Shimizu, S. Appl. Environ. Microbiol. 2001, 67, 5735-5739.

(36) Farinas, E. T.; Alcalde, M.; Arnold, F. H. Tetrahedron, in press.

(37) Otey, C.; Silberg, J. J.; Voigt, C. A.; Endelman, J. B.; Bandara, G.; Arnold, F. H. Chem. Biol., submitted.

(38) Wong, T. S.; Arnold, F. H.; Schwaneberg, U. Biotechnol. Bioeng., submitted. 


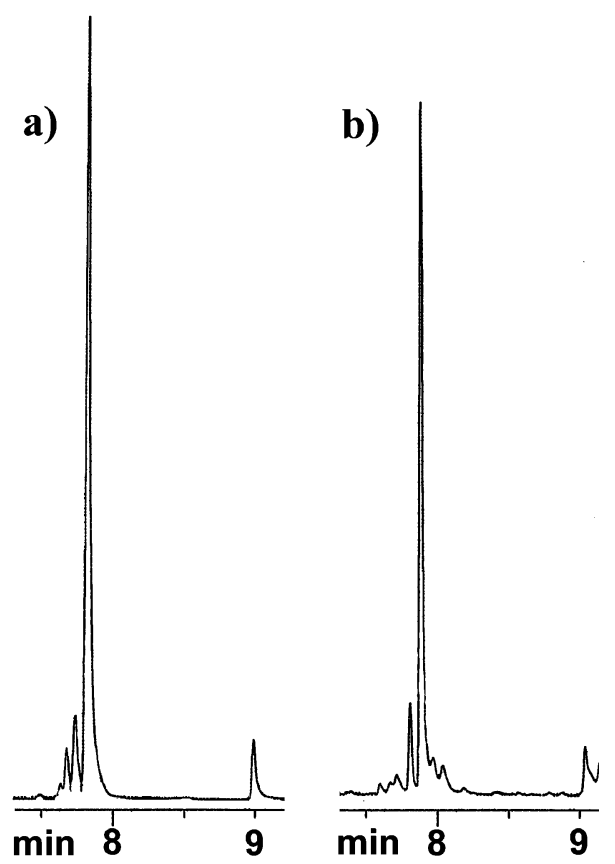

Figure 6. GC/FID analysis of the octane hydroxylation product using 9-10A-A328V as (a) purified protein and (b) a whole-cell catalyst. 3-Octanol elutes at $\sim 7.7 \mathrm{~min}, 2$-octanol elutes at $\sim 7.8 \mathrm{~min}$, and 1-octanol elutes at $\sim 9.0$ min.

thermostability. ${ }^{39}$ The regio- and enantioselective alkane hydroxylation activities reported here further demonstrate the functional flexibility of the BM-3 scaffold. We might (perhaps optimistically) regard BM-3 as a "one-enzyme-fits-all" oxidation catalyst.

Regioselective alkane hydroxylation requires a catalyst that can discriminate between very similar methylene carbons. In addition, there must be a mechanism to remove the hydroxylated substrate to prevent overoxidation. With the modifications presented in this work, the hydrophobic channel that serves as the active site of BM-3 provides the perfect environment for binding and oxidizing alkanes. It should be possible to make further improvements in the enantioselectivity of the 9-10A$\mathrm{A} 328 \mathrm{~V}$ and $1-12 \mathrm{G}$ biocatalysts, using directed evolution, as has been done for several other enzyme systems. ${ }^{40}$

\section{Experimental Procedures}

Materials. All liquid alkanes, product standards, and solvents were purchased from Sigma-Aldrich, Inc. (St. Louis, MO). Propane and dimethyl ether were purchased from Advanced Gas Technologies (Palm, $\mathrm{PA})$. Isocitrate dehydrogenase and $\mathrm{NADP}^{+}$were purchased from SigmaAldrich, Inc. (St. Louis, MO). NADPH was obtained from BioCatalytics, Inc. (Pasadena, CA).

Expression and Purification of P450 BM-3. P450 BM-3 was expressed and purified as described. ${ }^{18}$ The P450 BM-3 gene or mutants thereof, which include a silent mutation to introduce a SacI site 130 bp upstream of the end of the heme domain, was cloned behind the double tac promoter of the expression vector $\mathrm{pCW}$ ori ${ }^{17}$ (pBM3_WT186). E. coli $\mathrm{DH} 5 \alpha$, transformed with these plasmids, was used for expression of P450 BM-3 on a 500-mL scale as well as for expression in 96-well plates.

(39) Salazar, O.; Cirino, P. C.; Arnold, F. H. ChemBioChem. 2003, 4, 891893.

(40) Jaeger, K. E.; Eggert, T.; Eipper, A.; Reetz, M. T. Appl. Microbiol. Biotechnol. 2001, 55, 519-530.

13448 J. AM. CHEM. SOC. - VOL. 125, NO. 44, 2003
For protein production, supplemented terrific broth (TB) medium (500 mL, $100 \mu \mathrm{g} / \mathrm{mL}$ of ampicillin, $50 \mu \mathrm{g} / \mathrm{mL}$ of thiamine) was inoculated with an overnight culture $(1 \mathrm{~mL})$ and incubated at $30^{\circ} \mathrm{C}$ and $250 \mathrm{rpm}$ shaking. After $12 \mathrm{~h}$ of incubation, the rotation speed was lowered to $200 \mathrm{rpm}, \delta$-aminolevulinic acid hydrochloride (ALA; 0.5 $\mathrm{mM}$ ) was added, and expression was induced by addition of isopropyl$\beta$-D-thiogalactoside (IPTG; $1 \mathrm{mM}$ ). Cells were harvested by centrifugation $20-24 \mathrm{~h}$ after induction. The enzymes were purified following published procedures. ${ }^{17}$ Enzyme concentration was measured in triplicate from the CO-difference spectra. ${ }^{41}$

Recombination of P450 BM-3 Variants. The first generation of mutants was created by StEP recombination of mutant 139-3 ${ }^{18}$ with 15 other mutants from the same generation, as described. ${ }^{42}$ Mutant J was isolated from a library of $\sim 350$ mutants on the basis of its increased NADPH depletion rate using propane as a substrate.

Random Mutagenesis of P450 BM-3. Libraries for the second ( $\sim 1000$ mutants) and third $(\sim 1500$ mutants) generations were created by error-prone PCR using the GeneMorph Kit (Stratagene, La Jolla, CA) according to the manufacturer's protocol, using approximately 50 ng of plasmid DNA as template and primers BamHI-forw (5'ggaaacaggatccatcgatgc-3') and SacI-rev (5'-gtgaaggaataccgccaagc-3').

Site-Directed/Saturation Mutagenesis. Base mutations were introduced into mutant 9-10A by PCR overlap extension mutagenesis. ${ }^{43}$ Position A82 was mutated to $\mathrm{L}, \mathrm{I}, \mathrm{V}$, and $\mathrm{F}$ using mutagenic primers A82-forw (5'-ggagacgggttatttacaagc-3') and A82-rev (5'-gcttgtaaataacccgtctccaanaaaatcacg-3'). Position A328 was mutated to $\mathrm{V}$ using mutagenic primers A328V-forw (5'-gcttatggccaactgttcctgc- $\left.3^{\prime}\right)$ and A328V-rev ( $5^{\prime}$-gcaggaacagttggccataagc- $\left.3^{\prime}\right)$. For each mutation, two separate PCRs were performed, each using a perfectly complementary primer (BamHI-forw and SacI-rev) at the end of the sequence and a mutagenic primer. The resulting two overlapping fragments that contained the base substitution were then annealed in a second PCR to amplify the complete mutated gene.

Recombination of P450 BM-3 Variants. The fifth and last generation of mutants was created by recombination of mutants 1393, J, 9-10A, 9-10A-A82L, and 9-10A-A328V using a modification of Stemmer's DNA shuffling protocol. ${ }^{44}$

Preparation of Cell Lysates for High-Throughput Screening. Single colonies were picked and inoculated by a Qpix robot (Genetix, Beaverton, OR) into 1-mL, deep-well plates containing Luria-Bertani (LB) medium ( $350 \mu \mathrm{L}$, supplemented with $100 \mathrm{mg} / \mathrm{mL}$ of ampicillin). The plates were incubated at $30{ }^{\circ} \mathrm{C}, 250 \mathrm{rpm}$, and $80 \%$ relative humidity. After $24 \mathrm{~h}$, clones from this preculture were inoculated using a 96-pin replicator into 2-mL, deep-well plates containing TB medium (400 $\mu \mathrm{L}$, supplemented with $100 \mathrm{mg} / \mathrm{mL}$ of ampicillin, $10 \mu \mathrm{M}$ IPTG and $0.5 \mathrm{mM}$ ALA). The cultures were grown at $30^{\circ} \mathrm{C}, 250 \mathrm{rpm}$, and $80 \%$ relative humidity for another $24 \mathrm{~h}$. Cells were then pelleted and stored frozen at $-20^{\circ} \mathrm{C}$ until they were resuspended in $500 \mu \mathrm{L} 0.1 \mathrm{M}$ phosphate buffer $(0.1 \mathrm{M}, \mathrm{pH}=8,500 \mu \mathrm{L}$, containing $0.5 \mathrm{mg} / \mathrm{mL}$ of lysozyme, 2 units $/ \mathrm{mL}$ of DNaseI, and $10 \mathrm{mM} \mathrm{MgCl}$ ). After $60 \mathrm{~min}$ at $37^{\circ} \mathrm{C}$, the lysates were centrifuged, and the supernatant was diluted for activity measurements in 96-well microtiter plates.

High-Throughput NADPH Consumption Assay. The recombination library (resulting in mutant $\mathrm{J}$ ) and first mutant library (resulting in mutant 9-10A) were screened in 96-well plates for NADPH depletion using propane as substrate. To $30 \mu \mathrm{L}$ of E. coli supernatant, $170 \mu \mathrm{L}$ of phosphate buffer $(0.1 \mathrm{M}, \mathrm{pH} 8.0)$ saturated with propane was added. The reaction was initiated by addition of $50 \mu \mathrm{L}$ of NADPH $(0.8 \mathrm{mM})$, and NAPDH oxidation was monitored at $340 \mathrm{~nm}$ for 5 min using a Spectramax Plus microtiter plate reader (Molecular Devices, Sunnyvale, CA). The second library (no improved mutants found) was also screened

(41) Omura, T.; Sato, R. J. Biol. Chem. 1964, 239, 2370-2378.

(42) Zhao, H.; Giver, L.; Shao, Z.; Affholter, A.; Arnold, F. H. Nat. Biotechnol. 1998, 16, 258-261.

(43) Higuchi, R.; Krummel, B.; Saiki, R. K. Nucleic Acids Res. 1988, 16, 73517367.

(44) Joern, J. M. In Directed Evolution Library Creation: Methods and Protocols; Arnold, F. H., Georgiou, G., Eds.; Humana Press: Totowa, NJ, 2003; Vol. 231, pp 85-89. 
for $\mathrm{NADP}^{+}$formation using propane as substrate, as described. ${ }^{25,45}$ In brief, residual NADPH was destroyed with acid after an appropriate amount of time, followed by conversion of $\mathrm{NADP}^{+}$to a highly fluorescent alkali product at high $\mathrm{pH}$, which was then measured fluorometrically. Mutants were selected from these libraries based upon increased NADPH consumption.

High-Throughput Product-Based Screen. For direct measurement of product formation, a screen based on the demethylation of dimethyl ether was used in the later generations. To $30 \mu \mathrm{L}$ of $E$. coli supernatant, $120 \mu \mathrm{L}$ of phosphate buffer $(0.1 \mathrm{M}, \mathrm{pH}=8)$ saturated with dimethyl ether was added. After 2 min of incubation at room temperature, NADPH $(50 \mu \mathrm{L}, 1.0 \mathrm{mM})$ was added, and NADPH depletion was monitored as described above. Purpald (168 mM in $2 \mathrm{M} \mathrm{NaOH})$ was added 15 min after initiating the reaction to form a purple product with the formaldehyde that was generated upon demethylation of the substrate. The purple color was read approximately 15 min later at $550 \mathrm{~nm}$ using a Spectramax Plus microtiter plate reader. Mutants were selected from these libraries based upon their absorbance at $550 \mathrm{nM}$.

Alkane Hydroxylation Reactions. To measure alkane hydroxylation activities, ethanol solutions of liquid alkanes (hexane to decane) were added to buffer solutions containing the enzymes such that the total ethanol in the reaction mixture was $1 \%$. Several solvents, including ethanol, methanol, acetone, and dimethyl sulfoxide, were tested, and ethanol was shown to support the most product turnovers. Reactions with liquid alkanes that contained no cosolvent produced no detectable products. In the absence of substrate, NADPH has been reported to inactivate BM-3 by over-reducing the flavin cofactors in its reductase domain. ${ }^{46}$ To avoid this problem, substrate was added to the enzyme first and incubated for a few seconds before NADPH was added. Dioxygen was not added to the reactions, limiting the amount of possible product formed to the $225-250 \mu \mathrm{M}$ of oxygen present in airsaturated buffer. The addition of excess dioxygen to the reactions by direct bubbling or rapid stirring did not increase and often decreased the total product turnover, possibly by denaturing the protein. Reaction mixtures for all BM-3 mutants containing 0.5-1.0 $\mu \mathrm{M}$ enzyme produced $225-250 \mu \mathrm{M}$ products. We also noticed that total turnover numbers measured in systems containing less than $\sim 50 \mathrm{nM}$ protein were less than expected, i.e., $10 \mathrm{nM}$ protein in a reaction gave much less than half the total turnovers of a $20 \mathrm{nM}$ reaction. At very low concentrations of BM-3, the FMN cofactor has been reported to diffuse out of the protein and inactivate it. ${ }^{47}$ Given this fact and the dilution effects on total turnover that we witnessed, mutant $1-12 \mathrm{G}$ might be capable of even more turnovers than the $\sim 7500$ reported.

Reactions with the liquid alkanes, hexane, heptane, octane, nonane, and decane were performed in closed $20-\mathrm{mL}$ scintillation vials and stirred at low speed using magnetic stirring bars. In a typical reaction, purified protein (or cell lysate) was added to $4.45 \mathrm{~mL}$ of $0.1 \mathrm{M}$ potassium phosphate buffer $(\mathrm{pH}=8.0)$ such that the total protein concentration equaled $50 \mathrm{nM}$. The substrates were added to this solution as $50 \mu \mathrm{L}$ of $400 \mathrm{mM}$ ethanol solutions to give $4 \mathrm{mM}$ total substrate and $1 \%$ ethanol. After a few seconds, $500 \mu \mathrm{L}$ of $5 \mathrm{mM}$ NADPH in 0.1 $\mathrm{M}$ potassium phosphate buffer $(\mathrm{pH}=8.0)$ was added to the reaction, and the vial was capped. After $1-2 \mathrm{~h}$ of stirring at room temperature, a $1.5-\mathrm{mL}$ aliquot of the reaction was removed from the vial and quenched with $300 \mu \mathrm{L}$ of chloroform in a $2-\mathrm{mL}$ microcentrifuge tube. An internal standard containing $15 \mu \mathrm{L}$ of $10 \mathrm{mM}$ 1-pentanol or 3-octanol was added to the tube. The tube was vortexed and then centrifuged at $10000 \mathrm{~g}$ for $2 \mathrm{~min}$ in a microcentrifuge. The chloroform layer was removed with a pipet and analyzed by gas chromatography to determine total turnover numbers and product distributions. Control reactions

(45) Tsotsou, G. E.; Cass, A. E. G.; Gilardi, G. Biosens. Bioelectron. 2002, 17, $119-131$.

(46) Daff, S. N.; Chapman, S. K.; Turner, K. L.; Holt, R. A.; Govindaraj, S.; Poulos, T. L.; Munro, A. W. Biochemistry 1997, 36, 13816-13823.

(47) Strobel, H. W.; Hodgson, A. V.; Shen, S. In Cytochrome P450: Structure, Mechanism, and Biochemistry, 2nd ed.; Ortiz de Montellano, P. R., Ed.; Plenum Press: New York, 1995; pp 225-244. performed by repeating these steps without the addition of substrate revealed no detectable background levels of these specific products.

Chiral Analysis of Alkane Reactions. Chiral analysis of liquid alkane hydroxylation products was performed with a slight modification of an existing method, ${ }^{48}$ starting with extracting $9-\mathrm{mL}$ alkane reactions (using the reaction conditions above) with $2 \mathrm{~mL}$ of $\mathrm{CH}_{2} \mathrm{Cl}_{2}$ in a 15$\mathrm{mL}$ centrifuge tube. After centrifugation at $2800 \mathrm{~g}$ for $15 \mathrm{~min}$, the organic layer was removed with a pipet and dried over a small amount of anhydrous $\mathrm{MgSO}_{4}$. The $\mathrm{MgSO}_{4}$ was removed by filtration, and 1 $\mu \mathrm{L}$ of pyridine and $2.5 \mu \mathrm{L}(-)$-menthyl chloroformate were added. After an hour, $1 \mathrm{~mL}$ of deionized water was added to the reaction. After vortexing and letting the layers separate, the organic phase was removed with a pipet and dried with anhydrous $\mathrm{MgSO}_{4}$. The drying agent was again removed with a pipet filter and the remaining solution analyzed by gas chromatography. Control reactions were performed by repeating these steps without the addition of substrate and revealed no background levels of these specific products.

Propane Hydroxylation Reactions. Reactions using propane did not contain cosolvent because of potential competition between the solvent and the small substrate. These reactions were performed in propane-saturated buffer under an atmosphere of propane and dioxygen (provided by a balloon filled with the two gases). The addition of this atmosphere ensured that both gaseous substrates were saturated in the reaction solution, since a balloon of just propane or oxygen would dilute the concentration of the other gas. Total turnovers determined with this system were not dependent on oxygen concentration in the balloon (data not shown), illustrating that only the original $\sim 250 \mu \mathrm{M}$ of dioxygen in the buffer was available to the reaction. Additionally, we discovered that NADPH could neither be purchased nor easily purified in a form that contained less than 2-3\% ethanol, which interfered with analysis of the reaction products. For this reason, an NADPHregeneration system was used for propane reactions. ${ }^{29}$

Propane hydroxylation reactions were performed in 25 -mL Schlenk flasks. In a typical reaction, enzyme (either purified or in cell lysate) was added to $4.5 \mathrm{~mL}$ of propane-saturated $0.1 \mathrm{M}$ potassium phosphate buffer $(\mathrm{pH}=8.0)$ to a final concentration of 50-100 nM. To this mixture, $500 \mu \mathrm{L}$ of NADPH-regeneration system containing $1 \mathrm{mM}$ $\mathrm{NADP}^{+}, 100 \mathrm{mM}$ sodium isocitrate, and 20 units $/ \mathrm{mL}$ of isocitrate dehydrogenase was quickly added. The flask was topped with a balloon filled with equal amounts of propane and dioxygen. After stirring for $2 \mathrm{~h}$ at room temperature, the propane hydroxylation products were derivatized to alkyl nitrites using a published method. ${ }^{49}$ To the reaction mixture, $0.3 \mathrm{~g}$ of $\mathrm{NaNO}_{2}$ and $2 \mathrm{~mL}$ of $10 \mu \mathrm{M}$ chloroform in hexane was added, and the mixture cooled on ice. While on ice, $0.2 \mathrm{~mL}$ of concentrated $\mathrm{H}_{2} \mathrm{SO}_{4}$ was added. The flask was stoppered with a rubber stopper and stirred on ice for $15 \mathrm{~min}$. The reaction was rinsed into a separatory funnel with $20 \mathrm{~mL}$ of deionized water. The organic phase was washed twice with $20 \mathrm{~mL}$ of water and analyzed by gas chromatography. Control reactions were performed by repeating these steps without the substrate to correct for background levels of propanol.

Whole-Cell Reactions. The procedure for whole-cell reactions of E. coli $(\mathrm{DH} 5 \alpha)$ overexpressing mutants $9-10 \mathrm{~A}-\mathrm{A} 328 \mathrm{~V}$ and $1-12 \mathrm{G}$ was only slightly modified from Witholt's published method. ${ }^{30}$ An overnight culture of cells (in $3 \mathrm{~mL}$ of LB with $100 \mu \mathrm{g} / \mathrm{mL}$ of ampicillin) was used to innoculate $75 \mathrm{~mL}$ of $\mathrm{M} 9$-minimal medium containing $0.5 \%$ w/v glucose, $0.2 \mathrm{mM} \mathrm{CaCl}_{2} 5 \mathrm{mM} \mathrm{MgSO}_{4}$, and $100 \mu \mathrm{g} / \mathrm{mL}$ of ampicillin. The culture was then shaken for $24 \mathrm{~h}$ at $37{ }^{\circ} \mathrm{C}$ and 250 $\mathrm{rpm}$. The cells were collected by centrifugation at $2200 \mathrm{~g}$ for $10 \mathrm{~min}$ and resuspended in $20 \mathrm{~mL}$ of $0.2 \mathrm{M}$ potassium phosphate buffer $(\mathrm{pH}$ $=7.4$ ) containing $0.5 \%$ glucose, $100 \mu \mathrm{g} / \mathrm{mL}$ of ampicillin, $1 \mathrm{mM}$ IPTG, and $0.5 \mathrm{mM}$ ALA, $5 \mathrm{mM}$ alkane (from a $500 \mathrm{mM}$ stock of alkane in dimethyl sulfoxide). This mixture was shaken for $8 \mathrm{~h}$ at $37^{\circ} \mathrm{C}$ and 250 rpm. Product distributions were measured by gas chromatography after

(48) Westley, J. W.; Halpern, B. J. Org. Chem. 1968, 33, 3978-3980.

(49) Nguyen, H. T.; Takenaka, N.; Bandow, H.; Maeda, Y. Anal. Sci. 2001, 17, 639-643. 
extracting this culture with $1 \mathrm{~mL}$ of chloroform. Chiral analysis of the reaction products was performed after extracting the culture with $2 \mathrm{~mL}$ of $\mathrm{CH}_{2} \mathrm{Cl}_{2}$ and derivatizing the organic layer with (-)-menthyl chloroformate.

Gas Chromatography. Identification and quantification of analytes were performed using purchased standards and 5-point calibration curves with internal standards. All samples were injected at a volume of $1.0 \mu \mathrm{L}$, and analyses were performed at least in triplicate. Analyses of hydroxylation products were performed on a Hewlett-Packard 5890 Series II Plus gas chromatograph with both a flame-ionization (FID) and electron-capture detector (ECD) and fitted with a HP-7673 autosampler system. Direct analysis of hexane, heptane, octane, nonane, and decane hydroxylation products was performed on an HP-5 capillary column (cross-linked 5\% phenyl methyl siloxane, 30-m length, 0.32$\mathrm{mm}$ ID, $0.25-\mu \mathrm{m}$ film thickness) connected to the FID detector. A typical temperature program for separating the alcohol products is 250 ${ }^{\circ} \mathrm{C}$ inlet, $300{ }^{\circ} \mathrm{C}$ detector, $50{ }^{\circ} \mathrm{C}$ oven for $3 \mathrm{~min}$, then $10^{\circ} \mathrm{C} / \mathrm{min}$ gradient to $200{ }^{\circ} \mathrm{C}, 25^{\circ} \mathrm{C} / \mathrm{min}$ gradient to $250{ }^{\circ} \mathrm{C}$, and then $250{ }^{\circ} \mathrm{C}$ for $3 \mathrm{~min}$. The (-)-menthyl chloroformate-derivatized chiral products were separated as diastereomers on a CycloSil-B chiral capillary column (Agilent Technologies, 30-m length, 0.32-mm ID, 0.25- $\mu \mathrm{m}$ film thickness) connected to the FID detector. Each pair of diastereomers required a different temperature program for full resolution, but a typical program is as follows: (chiral heptanol analysis) $250{ }^{\circ} \mathrm{C}$ inlet, $300{ }^{\circ} \mathrm{C}$ detector, $100^{\circ} \mathrm{C}$ oven for $1 \mathrm{~min}$, then $10^{\circ} \mathrm{C} / \mathrm{min}$ gradient to $180^{\circ} \mathrm{C}$, hold at 180 ${ }^{\circ} \mathrm{C}$ for $10 \mathrm{~min}, 10^{\circ} \mathrm{C} / \mathrm{min}$ gradient to $250{ }^{\circ} \mathrm{C}$, and then $250{ }^{\circ} \mathrm{C}$ for 3 min. The propyl nitrite products were analyzed with an HP-1 capillary column (cross-linked 1\% phenyl methyl siloxane, 30-m length, 0.32 $\mathrm{mm}$ ID, $0.25-\mu \mathrm{m}$ film thickness) connected to an ECD detector. The temperature program for separating 1- and 2-propyl nitrites was: 250 ${ }^{\circ} \mathrm{C}$ inlet, $300{ }^{\circ} \mathrm{C}$ detector, $30{ }^{\circ} \mathrm{C}$ oven for $3 \mathrm{~min}, 20^{\circ} \mathrm{C} / \mathrm{min}$ gradient to $200{ }^{\circ} \mathrm{C}$, and then $200{ }^{\circ} \mathrm{C}$ for $5 \mathrm{~min}$.

Determination of NADPH Consumption Rates. The enzymes were purified and quantified as described above. Initial rates of NADPH consumption were measured at $25{ }^{\circ} \mathrm{C}$ in a BioSpec-1601 UV/vis spectrophotometer (Shimadzu, Columbia, MD). For the liquid alkanes, substrate stock solutions in ethanol $(10 \mu \mathrm{L})$ were added to the protein solution (100 nM, final concentration) in $0.1 \mathrm{M}$ potassium phosphate buffer $(\mathrm{pH}=8)$ and incubated for 2 min before initiating the reaction by addition of $200 \mu \mathrm{L}$ of NADPH $(0.8 \mathrm{mM})$, and the absorption at $340 \mathrm{~nm}$ was monitored. Rates were corrected for background NADPH consumption measured without substrate. Rates using propane were measured using $200 \mathrm{nM}$ protein, propane-saturated $0.1 \mathrm{M}$ potassium phosphate buffer $(\mathrm{pH}=8)$, and the same amount of NADPH. Rates were determined at least in triplicate.

Product Formation Rates: Oxidation of Octane. To determine octanol (and octanone) formation rates (measured at $21^{\circ} \mathrm{C}$ ), $5-\mathrm{mL}$ reactions containing $100 \mathrm{nM} \mathrm{P} 450$ and $4 \mathrm{mM}$ octane in $1 \%$ ethanol in $0.1 \mathrm{M}$ potassium phosphate buffer, $\mathrm{pH}=8$, were initiated by the addition of $500 \mu \mathrm{M}$ NADPH. Aliquots $(1 \mathrm{~mL})$ were removed from the reaction at 15 -s intervals and quenched in $2-\mathrm{mL}$ microcentrifuge tubes containing $300 \mu \mathrm{L}$ of chloroform, $100 \mu \mathrm{L}$ of $6 \mathrm{~N} \mathrm{HCl}$, and $10 \mu \mathrm{L}$ of $10 \mathrm{mM}$ 1-pentanol in ethanol. The tubes were vortexed and centrifuged at $\sim 10000 \mathrm{~g}$ for $2 \mathrm{~min}$ to separate the layers. The chloroform layer was removed and analyzed for total hydroxylated products by gas chromatography. Rates were determined in triplicate.

Product Formation Rates: Oxidation of Propane. Propanol formation rates were measured in 4-mL reactions containing $1 \mu \mathrm{M} \mathrm{P} 450$ and propane-saturated $0.1 \mathrm{M}$ potassium phosphate buffer, $(\mathrm{pH}=8)$ which were inititated with $500 \mu \mathrm{M}$ NADPH. Aliquots of this mixture (933 $\mu \mathrm{L}$ ) were removed at 20 -s intervals and quenched with $67 \mu \mathrm{L}$ of $6 \mathrm{~N} \mathrm{HCl}$ containing $3 \mathrm{mM}$ 1-pentanol internal standard $(200 \mu \mathrm{M}$ final concentration). The samples were analyzed by GC-FID fitted with an HP FFAP (cross-linked FFAP, 30-m length, 0.25-mm ID, 0.25- $\mu \mathrm{m}$ film thickness) using the temperature program: $250{ }^{\circ} \mathrm{C}$ inlet, $300{ }^{\circ} \mathrm{C}$ detector, $50{ }^{\circ} \mathrm{C}$ oven for $3 \mathrm{~min}$, then $10^{\circ} \mathrm{C} / \mathrm{min}$ gradient to $200{ }^{\circ} \mathrm{C}, 25^{\circ} \mathrm{C} / \mathrm{min}$ gradient to $220^{\circ} \mathrm{C}$, then $220^{\circ} \mathrm{C}$ for $3 \mathrm{~min}$. Rates were determined in triplicate.

Acknowledgment. The authors thank Dr. Nathan Dalleska for his assistance with the gas chromatography. This work is supported by the National Science Foundation (BES 9981770).

JA0303790 